\title{
Vasomotor symptoms and well-being in the climacteric years
}

\author{
F.P.M.J. Groeneveld ${ }^{a, *}$, F.P. Bareman ${ }^{\mathrm{a}}$, R. Barentsen ${ }^{\mathrm{d}}$, H.J. Dokter ${ }^{\mathrm{a}}$, \\ A.C. Drogendijk ${ }^{\mathrm{b}}$, A.W. Hoes ${ }^{\mathrm{c}}$ \\ ${ }^{a}$ Department of General Practice, Erasmus University of Rotterdam, Postbox 1738, 3000 DR Rotterdam, The Netherlands \\ ${ }^{b}$ Department of Obstetrics \& Gynaecology, Erasmus University of Rotterdam, Rotterdam, The Netherlands \\ 'Department of Epidemiology \& Biostatistics, Erasmus University of Rotterdam, Rotterdam, The Netherlands \\ ${ }^{\mathrm{d} D e p a r t m e n t}$ of Obstetrics \& Gynaecology, Elkerliek Hospital, Helmond, The Netherlands
}

Received 16 June 1995; revised 15 November 1995; accepted 22 November 1995

\begin{abstract}
Objectives: To determine more closely the relationship between vasomotor symptoms, well-being and climacteric status according to the last menstrual bleeding and according to the women themselves. Methods: A population-based cross-sectional study was executed using a postal questionnaire. Well-being of women with and without vasomotor symptoms was compared, for the different menopausal statuses. All 2729 women living in a commuter suburb of Rotterdam aged 45-60 years were approached of whom $1947(71.3 \%)$ responded. Well-being was measured by the Inventory of Subjective Health (ISH) and three subscales of the Sickness Impact Profile (SIP). Results: The results showed that the relationship between vasomotor symptoms and well-being was dependent on climacteric status. Preand (middle and late) postmenopausal women with vasomotor symptoms more often experienced a relatively lower level of well-being compared to women without these symptoms. However, when the prevalence of vasomotor symptoms is as its peak, i.e. in late perimenopause, a difference in the level of well-being between women with and without vasomotor symptoms was absent. Conclusions: It is concluded that well-being and vasomotor symptoms were inversely related in all menopausal statuses except for the (late) perimenopausal phase. For this no somatic explanation seems plausible. A more social scientific explanation is suggested.
\end{abstract}

Keywords: Vasomotor symptoms; Well-being; Climacteric status

\section{Introduction}

Early studies of the climacteric reported a range of symptoms that occur more frequently among women whose menstrual cycles have changed. These include hot flushes, night sweats, lethargy, forgetfulness tiredness, crying spells, irritability

\footnotetext{
* Corresponding author. Fax: $(+31-10) 4360717$.
}

and headache [1-4]. Later studies differentiated between typical symptoms that are strongly related to the climacteric (i.e. vasomotor symptoms and vaginal dryness) and atypical symptoms that are weakly associated. These atypical symptoms appeared to be more related to concurrent social, psychological and physically bothersome changes than to the climacteric per se [5-7]. Since the study of mere symptoms may give a limited view 
of the experiences of women in the climacteric years, other studies have addressed the association between climacteric and measures of well-being. These studies pointed out that (emotional) wellbeing is not much adversely affected by the climacteric [8-12]. However, Oldenhave et al. [13] recently concluded that the prevalence of vasomotor symptoms was highest in the late premenopause and early postmenopause (about $85 \%$ ) and that this increase of vasomotor symptoms was related to an overall reduced level of well-being. Apparently, equivocal conceptions of the association between climacteric status and well-being exist, when vasomotor symptoms are taken into account.

The aim of our study was to examine more closely the relationship between vasomotor symptoms and well-being for women in the separate climacteric status. Climacteric status was defined in two ways: according to self-perception and according to last menstrual bleeding.

\section{Methods}

This study is part of a larger study aimed at assessing the relationships between the climacteric, well-being, women's attitude towards menopause, medical attention and the use of hormone replacement therapy. The methodology of this study has been reported by us in detail elsewhere [10]. In short, from the municipal authorities of Krimpen aan den IJssel, a commuter suburb of Rotterdam with approximately 28000 inhabitants, names and addresses of all 2729 women aged 45-60 years were obtained. In May 1990 they were sent a questionnaire; 1947 women responded (response $71.3 \%$ ). The comparison between respondents did not reveal any statistically significant differences in age, menopausal status, hysterectomy, estrogen therapy, level of education, work outside the home or medical attention. The study received approval from the Medical Ethical Committee of the Erasmus University and Academic Hospital, Dijkzigt in Rotterdam.

Well-being was measured by two validated inventories: the Inventory of Subjective Health (ISH) and the Sickness Impact Profile (SIP). The
ISH has proven to be a sensitive instrument to detect health problems. In recent years it has been used in several Dutch surveys to quantify subjective health status [14-16]. In a large representative study in the Netherlands Cronbach's $x$ equalled 0.87 and the ratio of the eigenvalues of the first and second principal component equalled $16.2 / 4.4=3.7$, both reflecting a strong unidimensional scale. The ISH includes 49 items, concerning the experience in the past 2 weeks of complaints like pains in the chest, shaking hands, headache, sneezing and less appetite. On every item the respondent was asked whether it had been experienced during the last 2 weeks. All items required either 'yes' or 'no' responses. The sum score of all responses was computed, the maximum score being 49. The SIP was developed in the United States as a behaviourally based measure of the impact of sickness [17]. In this study, the Dutch validated version was used [18] We selected subscales at which, according to literature [1-4] a possible effect of the climacteric on behaviour may be established. Therefore, we took the SIP subscales which measure the psycho-social impact on well-being: emotions, feelings and sensations (nine items), social interaction (18 items) and intellectual functioning and alertness (10 items).

Women were categorized as having vasomotor symptoms if they reported hot flushes and/or severe sweating on the questionnaire. The presence of severe sweating was assessed by using both a closed and an open question, whereas the presence of hot flushes was assessed using an open question only. The closed questions were incorporated in a symptom checklist, where the women could encircle either yes or no when they had regularly experienced a symptom during the last 2 weeks. In the open question the women could indicate any symptom they experienced during the last 4 weeks.

The climacteric status of women was classified according to menstrual pattern characteristics and to the number of months or years since the last menstrual bleeding prior to the completion of the questionnaire. We defined six categories [10]. Women who had had a menstruation within 12 months and whose menstrual pattern did not 
change (premenopausal), women who had experienced a change in the menstrual cycles in the preceding year with a last menstrual bleeding occurring 3 months or less (perimenopausal I) or 4-12 months ago (perimenopausal II), women whose last menstrual bleeding occurred 1-2.5 years ago (postmenopausal I), 2.5-4.5 years ago (postmenopausal II) and more than 4.5 years ago (postmenopausal III). As some women filled out the year of the last menstrual bleeding only and not the exact month, a classification was chosen which coincided with the calendar year. Women who had undergone hysterectomy and women who had used estrogen therapy in the 6 months prior to answering the questionnaire $(n=473)$, were excluded from the analyses as they can not be classified according to climacteric status. The women were also asked to rate their climacteric phase themselves by choosing one out of five categories.

Prevalences of vasomotor symptoms were computed for women in the different climacteric categories. Subsequently, a logistic regression analysis was performed with the dichotomized scores of well-being as the dependent variable and the presence of vasomotor symptoms as independent variable. Well-being scores were dichotomized around the median. In an earlier study we reported on the relationship between well-being and body mass index, smoking, education, the woman's employment status, parity, the way of cohabitation, age difference between the partners and the employment status of the partner [10]. In this analysis age, education and body mass index were related on a $P<0.01$ level to one or more of the four measures of well-being and were therefore entered in the logistic regression equation. Odds ratios with $95 \%$ confidence intervals were computed for the six menopausal statuses defined according to last menstrual bleeding as well as for the five categories of menopausal status according to the women themselves. In this study the odds ratios express the likelihood of women with vasomotor symptoms compared to women without these symptoms of having a score of well-being above the median. A relatively high score means a relatively low level of well-being.

\section{Results}

In Table 1, the prevalence of vasomotor symptoms is shown for the six climacteric statuses according to last menstrual bleeding. The prevalence varied from $25.0 \%$ in premenopause, to $69.1 \%$ in late perimenopause (peri II) and was $38.9 \%$ in late postmenopause.

The odds ratios of women with vasomotor symptoms as compared to women without these symptoms of experiencing a level of well-being below the median are also shown in Table 1.

Premenopausal women with vasomotor symptoms more often experienced a lower level on all four measures of well-being compared to women without these symptoms. Women with vasomotor symptoms had 4.8 (95\% CI, 2.3-9.7) times more often a lower level of well-being on the ISH. The corresponding odds ratio for the SIP social functioning was $1.9(95 \% \mathrm{CI}, 1.0-3.5)$, for the SIP emotions, feelings and sensations $2.2(95 \% \mathrm{CI}$, $1.2-4.0)$ and for SIP intellectual functioning and alertness 2.7 (95\% CI, 1.4-5.0).

Early perimenopausal women (peri I) with vasomotor symptoms were somewhat more likely to experience a lower level of well-being than women without these symptoms: the odds ratios being slightly higher than 1.0, except for the ISH (odds ratio, $2.1 ; 95 \% \mathrm{Cl}, 1.1-4.0)$. In contrast, late perimenopausal women (peri II) with vasomotor symptoms less often report a relatively low level of well-being on all scales. However, none of these odds ratios were statistically significant.

For early postmenopausal women (post I) no association between vasomotor symptoms and the SIP intellectual functioning and alertness and the SIP emotions, feelings and sensations was found, whereas for the ISH and the SIP social functioning odds ratios of $1.9(95 \% \mathrm{CI}, 0.8-4.8)$ and 2.9 (95\% CI, 1.2-7.1) respectively were found. Among middle postmenopausal women (post II) all women with vasomotor symptoms reported a relatively lower level of well-being. Finally, for late postmenopausal women (post HI) with vasomotor symptoms all measures showed an odds ratio higher than 1.0. Statistically significant odds ratios were established on the ISH (odds ratio, $2.1 ; 95 \% \mathrm{CI}, 1.3-3.4)$ and the SIP social functioning (odds ratio, $1.9 ; 95 \% \mathrm{CI}, 1.2-3.1$ ) only. 
Table 1

Prevalence and odds ratios of vasomotor symptoms for menopausal status according to last menstrual bleeding

\begin{tabular}{|c|c|c|c|c|c|c|}
\hline \multirow[t]{2}{*}{ Characteristic } & \multicolumn{6}{|c|}{ Menopausal status according to last menstrual bleeding } \\
\hline & Pre & Peri I & Peri II & Post I & Post II & Post III \\
\hline Number & 274 & 226 & 83 & 140 & 153 & 466 \\
\hline Prevalence of vasomotor symptoms & $25.0 \%$ & $41.0 \%$ & $69.1 \%$ & $61.3 \%$ & $58.4 \%$ & $38.9 \%$ \\
\hline \multicolumn{7}{|l|}{ Measure of well-being } \\
\hline \multicolumn{7}{|l|}{ ISH } \\
\hline Odds Ratio & 4.8 & 2.1 & 0.6 & 1.9. & 5.8 & 2.1 \\
\hline $95 \%$ CI & $2.3-9.7$ & $1.1-4.0$ & $0.2-2.3$ & $0.8-4.8$ & $2.4-14.0$ & $1.3-3.4$ \\
\hline \multicolumn{7}{|l|}{ SIP social functioning } \\
\hline Odds Ratio & 1.9 & 1.0 & 0.4 & 2.9 & 1.4 & 1.9 \\
\hline $95 \% \mathrm{CI}$ & $1.0-3.3$ & $0.5-1.8$ & $0.1-1.2$ & $1.2-7.1$ & $0.6-3.0$ & $1.2-3.1$ \\
\hline \multicolumn{7}{|l|}{ SIP emotions, feelings and sensations } \\
\hline Odds Ratio & 2.2 & 1.5 & 0.5 & 0.8 & 2.0 & 1.4 \\
\hline $95 \% \mathrm{Cl}$ & $1.2-4.0$ & $0.8-2.7$ & $0.2-1.6$ & $0.4-1.9$ & $0.8-4.7$ & $0.9-2.1$ \\
\hline \multicolumn{7}{|c|}{ SIP intellectual functioning and alertness } \\
\hline Odds Ratio & 2.7 & 1.2 & 0.8 & 1.0 & 1.5 & 1.3 \\
\hline $95 \% \mathrm{CI}$ & $1.4-5.0$ & $0.6-2.1$ & $0.3-2.5$ & $0.4-2.3$ & $0.7-3.5$ & $0.8-2.0$ \\
\hline
\end{tabular}

Odds ratio of women with vasomotor symptoms compared to women without symptoms of being above the median on four measures of well-being. A score above the median means a relatively lower level of well-being. Figures are presented separately for menopausal status according to last menstrual bleeding. Odds ratios are adjusted for differences in age, education and body mass index.

In Table 2 the relationship between vasomotor symptoms and the level of well-being is shown for the menopausal phases categorized according to the women themselves. The same pattern emerged. Here too, women with vasomotor symptoms who perceive themselves as not menopausal or menopausal long ago had significantly more often a relatively low level of well-being, whereas women with vasomotor symptoms who perceive themselves as in the middle of menopause had odds ratios that are notably lower.

\section{Discussion}

Population based studies established no major difference in well-being between pre-, peri- and postmenopausal women $[6-10,12]$. Studies in which a distinction was made between women with or without vasomotor symptoms showed a considerably lower level of well-being for women with these symptoms $[13,19]$. In this cross-sectional study we also found a clear relationship between vasomotor symptoms and well-being which depended on climacteric status. We found that pre and (middle and late) postmenopausal women with vasomotor symptoms more often experienced a relatively low level of well-being compared to women without these symptoms. However, in contrast to the above mentioned studies, a difference in the level of well-being between women with and without vasomotor symptoms was absent in late perimenopause; the phase in which the prevalence of vasomotor symptoms is at its peak.

An explanation for the fact that Oldenhave did not detect an absence of the relationship in perimenopausal women may be found in the differences between the measurement instruments applied to quantify health status.

In Daly's recently published study, it was concluded that the quality of life of women with menopausal symptoms may be severely compromised and that perceived improvements in quality of life in users of hormone replacement therapy seem to be substantial [19]. The methodology of 
Table 2

Prevalence and odds ratios of vasomotor symptoms for menopausal status according to the women themselves

\begin{tabular}{|c|c|c|c|c|c|}
\hline \multirow[t]{2}{*}{ Characteristic } & \multicolumn{5}{|c|}{ Menopausal status according to the women themselves } \\
\hline & $\begin{array}{l}\text { Not reached } \\
\text { menopause }\end{array}$ & $\begin{array}{l}\text { Just reached } \\
\text { menopause }\end{array}$ & $\begin{array}{l}\text { Middle of } \\
\text { menopause }\end{array}$ & End of menopause & $\begin{array}{l}\text { Menopause long } \\
\text { ago }\end{array}$ \\
\hline Number & 265 & 242 & 324 & 224 & 354 \\
\hline $\begin{array}{l}\text { Prevalence of } \\
\text { vasomotor symptoms }\end{array}$ & $17.2 \%$ & $45.4 \%$ & $68.3 \%$ & $58.8 \%$ & $27.7 \%$ \\
\hline \multicolumn{6}{|c|}{$\begin{array}{l}\text { Measure of well-being } \\
\text { ISH }\end{array}$} \\
\hline Odds Ratio & 4.4 & 2.1 & 1.5 & 1.4 & 2.8 \\
\hline $95 \% \mathrm{CI}$ & $2.0-9.6$ & $1.1-3.9$ & $0.8-2.8$ & $0.7-2.8$ & $1.5-5.2$ \\
\hline \multicolumn{6}{|c|}{ SIP social functioning } \\
\hline Odds Ratio & 2.3 & 0.7 & 1.2 & 1.7 & 1.8 \\
\hline $95 \% \mathrm{CI}$ & $1.1-4.9$ & $0.4-1.4$ & $0.7-2.1$ & $0.8-3.3$ & $1.0-3.2$ \\
\hline \multicolumn{6}{|c|}{ SIP emotions, feelings and sensations } \\
\hline Odds Ratio & 2.6 & 1.0 & 0.8 & 1.0 & 1.8 \\
\hline $95 \% \mathrm{CI}$ & $1.3-5.3$ & $0.5-1.7$ & $0.4-1.3$ & $0.5-1.8$ & $1.0-3.1$ \\
\hline \multicolumn{6}{|c|}{ SIP intellectual functioning and alertness } \\
\hline Odds Ratio & 3.8 & 0.9 & 0.9 & 1.3 & 1.4 \\
\hline $95 \% \mathrm{Cl}$ & $1.8-7.8$ & $0.5-1.7$ & $0.5-1.5$ & $0.7-2.5$ & $0.8-2.4$ \\
\hline
\end{tabular}

Odds ratios of women with vasomotor symptoms compared to women without symptoms of being above the median on four measures of well-being. A score above the median means a relatively lower level of well-being. Figures are presented separately for menopausal status according to the women themselves. Odds ratios are adjusted for differences in age, cducation and body mass index.

that study is different from ours. Firstly, women who suffered from bothersome complaints mainly were recruited whereas we recruited from a general population. Secondly, imagination of (severity of) complaints was used, in contrast to actual experience in our study.

This study yielded an unexpected observation: vasomotor symptoms were negatively related with well-being in all menopausal phases, with the exception of the late perimenopausal phasc. Although the prevalence of vasomotor symptoms depends on the climacteric status, it is not obvious why in late perimenopausal women vasomotor symptoms were not related to well-being, whereas in pre- and postmenopausal women they were.

Differences in hormone level could provide an explanation. However, no study thus far has shown a clear relationship between serum hormone levels and vasomotor symptoms [20,21]. Even if such a relationship exists it would still be difficult to explain the absence of a negative impact of vasomotor symptoms on well-being in perimenopausal women. Apart from a biological approach we think a social scientific explanation may be worthwhile. Social scientists stress the importance of the context in which a symptom is experienced [22,23]. Aubuchon et al. conclude that social expectancies influence the report of perimenstrual discomfort. Zola stated that there are two ways in which symptoms indicated in one part of a population may be ignored in another part. Firstly, when a symptom's prevalence is high, this condition may be perceived as the normal state. Secondly, it is the fit of certain symptoms with a society's major values $(75 \%$ of the women in this study agreed with the statement 'physical changes in the climacteric are natural' [24]), which accounts for the degree of attention they receive. This theory implies that vasomotor symptoms will be experienced as 'normal' in peri- 
menopause, whereas the presence of vasomotor symptoms in pre- and postmenopausal women will be more difficult to understand. This line of reasoning is only valid when perimenopausal women according to last menstrual bleeding perceive themselves as such. In fact the results about the relationship between vasomotor symptoms and well-being for the climacteric status as perceived by the women themselves confirm this view.

An advantage of this study lies in its representativity. This study was performed in a nonselected population. The response rate was adequate and a sample of non-respondents did not differ from the respondents on a number of characteristics. No emphasis was placed on the climacteric. A limitation of this study is its cross-sectional design. To assess whether vasomotor symptoms induce a lower level of well-being or vice versa, longitudinal studies are necessary.

It is beyond question that hormone replacement therapy relieves vasomotor symptoms and thereby may improve a woman's well-being. Placebos also proved to be beneficial, albeit to a lesser degree than hormone replacement, in the treatment of vasomotor symptoms [25]. Presumably vasomotor symptoms can be influenced by other than pharmacological approaches. This is also supported by Whitehead's study [26]. in which he claims that explanation and reassurance were sufficiently helpful for $40 \%$ of the women seeking help at menopausal clinics. In conclusion, this study showed that well-being and vasomotor symptoms were related in all menopausal statuses except for the perimenopausal phase. For this no somatic explanation seems plausible. A more social scientific explanation was therefore suggested.

\section{Acknowledgements}

This work was supported by grants form Ciba-Geigy, Schering and Wyeth-Ayerst. We would like to thank Mrs De Haan-Meynell for her helpful comments.

\section{References}

[1] Neugarten BL, Kraines RI. Menopausal symptoms in women of various ages. Psychosom Med 1965: 27: $266-$ 273.

[2] Jaszmann I, van Lith ND, Zatt JCA. The perimenopausal symptoms: the statistical analysis of a survey. Part A and B. Med Gynaecol Sociol 1969; 4: 268-277.

[3] Greene JG. A factor analytic study of climacteric symptoms. J Psychosom Res 1976: 20: 425-430.

[4] Dennerstein L, Burrows GD. A review of studies of the psychological symptoms found at the menopause. Maturitas 1978; 1: 55-64.

[5] Cooke DJ. Social support and stressful life events during mid-life. Maturitas 1985; 7: 303-313.

[6] Hunter M, Battersby R, Whitehead M. Relationships between psychological symptoms, somatic complaints and menopausal status. Maturitas 1986; 8: 217-228.

[7] Holte A, Mikkelsen A. Psychosocial determinants of climacteric complaints. Maturitas 1991; 13: 205-215.

[8] Hunter MS. Emotional well-being, sexual behaviour and hormone replacement therapy. Maturitas 1990; 12: 299 314.

[9] Kaufert PA, Gilbert P, Tate R. The Mannitoba project: A re-examination of the links between menopause and depression. Maturitas 1991; 14:143-155.

[10] Groeneveld FPMJ, Bareman FP, Barentsen R, Dokter HJ, Drogendijk AC, Hoes AW. The climacteric and wcll-being. J Psychosom Obstet Gynaecol 1993; 14: 127 143.

[11] Green JG, Visser APh. Longitudinal studies: comparative conclusions. Maturitas 1992; 14: 157-160.

[12] Matthews KA, Wing RR, Kuller LH, Meilahn EN, Kelsey SF, Costello EJ, Caggiula AW. J Consult Clin Psychol 1990; 58: 345-351.

[13] Oldenhave A, Jaszmann LJB, Haspels AA, Everaerd WThAm. Impact of climacteric on well-being. Am I Obstet Gynaecol 1993; 168: 772-780.

[14] Visser APh. De betekenis van de VOEG: enkele gegevens over begripsvaliditeit. Gezondheid \& Samenleving 1983; 4: $177-185$.

[15] Reek van J, Diederiks J, Philipsen J, Zutphen van W, Seeelen A. Subjective complaints and blood pressure. J Psychosom Res 1982; 26: 155-165.

[16] Huygen FJA, Mokkink HGA, Smits AJA, Son van JAJ, Meyboom WA, Eyk van JThM. Relationship between the working styles of general practitioners and the health status of their patients. Br J Gen Pract 1992; 42: 141-144.

[17] Pollard WE, Bobbit RA, Bergner M, Martin DP, Gilson MA, BS. The Sickness Impact Profile: reliability of a Health Status Measure. Med Care 1976; 14: 146-155.

[18] Jacobs HM, Luttik A, Touw-Otten FWMM, Melker de RA. De 'Sickness Impact Profile'; resultaten van een valideringsonderzoek van de Nederlandse versic. Ncd Tijdschr Geneesk 1990; 134: 1950-1954.

[19] Daly E, Gray A, Barlow D, McPherson K, Roche M, Vessey M. Measuring the impact of menopausal symptoms on quality of life. Br Med J 1993; 307: 836-840. 
[20] Ginsburg J, Hardiman P. What do we know about the pathogenesis of the menopausal hot flush? In: SitrukWare R, Utian WH, eds. The menopause and hormonal replacement therapy. New York: Marcel Dekker inc, $1991 ; 15-46$.

[21] Gow SM, Turner EI, Glasier A. The clinical biochemistry of the menopause and hormone replacement therapy. Ann Clin Biochem 1994; 31: 509-529.

[22] Aubuchon PG, Calhoun KS. Menstrual cycle symptomatology the role of social expectancy and experimental demand characteristics. Psychosom Med 1985; 47: 35-45.

[23] Zola IK. Culture and symptoms - an analysis of patients' presenting complaints. Am Social Rev 1966; 31 : $615-630$.
[24] Groeneveld FPMJ, Bareman FP, Barentsen R, Hoes AW, Dokter HJ, Drogendijk AC. Relationships between attitude towards menopause, well-being and medical attention, among women aged 45-60 years. Maturitas 1993 : 17: $77-88$.

[25] Tulandi T, Lal S. Menopausal hot flush. Obstet Gynecol Surv 1985; 40: 553-563.

[26] Whitehead MI. The menopause. Part A: Hormone "replacement" therapy-controversies. In: Dennerstein L, Burrows G, eds. Controversies Handbook of Psychosomatic Obstetrics and Gynaecology. Amsterdam: Elsevier Biomedical Press, 1983; 445-481. 